\title{
O Pensamento de Fronteira de Carolina Maria de Jesus
}

\author{
Érika Soares Oliveira \\ ${ }^{1}$ Universidade Federal de Alagoas, AL, Brasil.
}

\begin{abstract}
Resumo: Este texto tem como objetivo refletir a respeito da pretensa universalidade do conhecimento, discutindo o modo como explicações eurocêntricas sobre o mundo acabam por orientar nossa produção acadêmica. Parte-se da ideia de que a colonialidade epistemológica, ao designar aquelas(es) que teriam direito de produzir teorias, acaba por criar uma série de não existências o que, em última instância, leva ao desperdício de experiências. A partir do conceito de pensamento de fronteira, desenvolvido pela perspectiva decolonial, trago a obra da escritora Carolina Maria de Jesus para discutir a possibilidade de se pensar a realidade a partir da ferida aberta pela diferença colonial. Com suas narrativas, Carolina permite que se compreenda que o conhecimento é gerado a partir de uma geopolítica que procura excluir algumas vozes e que, a despeito de incontáveis estratégias de subalternização, essas vozes teimam em resistir. Desejase aqui desempalidecer epistemes e produzir olhares "outros" para a produção de conhecimento em psicologia social.
\end{abstract}

Palavras-chave: Colonialidade, Feminismos, Intervenções Psicossociais, Carolina Maria de Jesus.

\section{Carolina Maria de Jesus' Border Thinking}

\begin{abstract}
This text reflects on the alleged universality of knowledge, discussing the way Eurocentric explanations of the world end up guiding our academic production. It is assumed that epistemological coloniality, by designating those who have the right to produce theories, creates a series of nonexistences that ultimately lead to waste of experiences. Based on the concept of border thinking developed by the decolonial perspective, I discuss the work of the writer Carolina Maria de Jesus and the possibility of thinking about reality according to the wound opened by colonial difference. Through her narratives, Carolina allows us to comprehend that knowledge is generated from geopolitics that tries to exclude some voices and that, despite countless strategies for subalternation, those voices insist on resisting. This paper should thus serve to depart from epistemes and to produce "other" perspectives for the production of knowledge in social psychology.
\end{abstract}

Keywords: Coloniality, Feminisms, Psychosocial Interventions, Carolina Maria de Jesus.

\section{El Pensamiento de frontera de Carolina Maria de Jesus}

Resumen: Este texto tiene como objetivo reflexionar sobre la pretendida universalidad del conocimiento, discutiendo cómo explicaciones eurocéntricas sobre el mundo acaban por orientar nuestra producción académica. Se parte de la idea de que la colonialidad epistemológica, al designar aquellas que tendrían derecho a producir teorías, acaba por crear una serie de no-existencias, lo que, en última instancia, lleva al desperdicio de experiencias. A partir del 
concepto de pensamiento de frontera, desarrollado por la perspectiva decolonial, utilizo la obra de la escritora Carolina Maria de Jesus para discutir la posibilidad de pensar la realidad a partir de la herida abierta por la diferencia colonial. Las narrativas de Carolina permiten comprender que el conocimiento es generado a partir de una geopolítica que busca excluir algunas voces y que, a pesar de incontables estrategias de subalternización, esas voces resisten. Se busca aquí desempalidecer epistemes y producir "otras" miradas para la producción de conocimiento en psicología social.

Palabras clave: Colonialidad, Feminismos, Intervenciones Psicosociales, Carolina Maria de Jesus.

\section{Com a cabeça cheia de versos... ${ }^{1}$}

\section{Tenho de descarregar a cabeça de toda esta inspiração que me atormenta dia e noite}

(Carolina Maria de Jesus) ${ }^{2}$.

Este artigo é fruto de discussões que tomam como referência a vida e obra da escritora mineira Carolina Maria de Jesus (1914-1977) e o estudo de seu território existencial a fim de fornecer novos arranjos para se pensar o conhecimento produzido pela psicologia social. Carolina ficou conhecida na década de 1960 por publicar um diário ${ }^{3}$ sobre o cotidiano na favela. Para tanto, ela relatava nos cadernos que encontrava no lixo, as dificuldades de se viver naquele lugar, numa narrativa que rompia com as padronizações linguísticas já que ela frequentou os bancos escolares apenas por dois anos. Seu legado, contudo, não se resume à análise que ela faz do Brasil nas décadas de 1950 e 1960. Em diferentes cadernos (de contabilidade, escolares, de entrada e saída de mercadorias) que ia encontrando em suas andanças, ela escrevia romances, poesias, peças de teatro, letras de música e provérbios, somando cinco mil folhas escritas. Além disso, tentou ser atriz e cantora, desejando, inclusive, ser mais reconhecida por sua poesia do que pela escrita de um diário (Fernandez, 2014). Conhecida, em grande medida, pelo ineditismo das denúncias produzidas em seu diário, ela foi, muitas vezes, desencorajada a produzir seus escritos literários, o que a levou a publicá-los por conta própria, ainda que isso tenha resultado em insucesso. O que vale chamar atenção, contudo, é que, antes de conhecer o jornalista Audálio
Dantas $^{4}$ e apresentar-lhe seus manuscritos, ela já era conhecida em rádios e redações de jornais, tendo seus poemas publicados em alguns deles ou mesmo por ter participado como colaboradora em um jornal. De acordo com um de seus biógrafos, Tom Farias (2017): "Na cidade de São Paulo, especialmente, Carolina conseguia acesso às redações de jornais e rádios, sem muitas dificuldades, apoiada ou recomendada por indicações, no geral, políticas” (p. 179).

Carolina pode ser caracterizada como alguém que concebia o ato de escrever como uma necessidade imperiosa, incontrolável, de ordenar o mundo em palavras, de maneira febril, como se cumprisse, predestinadamente, uma vocação. Ela simplesmente atendia a esse desígnio, escrevendo nas folhas que encontrava em sua frente, com os recursos que tinhae que também não tinha. Tanto é que uma de suas estudiosas, Raffaela Fernandez (2014), comenta que acessou alguns dos escritos que Carolina carregava consigo e que muitos deles ainda traziam o odor de lixo, passados tantos anos, revelando o lugar de onde foram retirados. Carolina escrevia como quem, nas palavras dela, sofria de um vício, o vício da poesia (Farias, 2017). Farias (2017), traz uma das falas dela na redação do jornal paulistano $A$ Noite naquela época: "Tudo tenho feito para torcer a linha do meu destino e esquecer a tortura dos versos que me enchem a cabeça, mas eles brotam do meu pensamento e eu não tenho outro remédio senão dar-lhes expansão. Está aqui o fruto das minhas ideias" (p. 118).

Assim, a escrita que trago aqui resulta dos constantes deslocamentos que tenho procurado viver e também daqueles que tenho tentado provocar em

\footnotetext{
${ }^{1}$ Publicado na Folha da Manhã, esse poema de Carolina inicia da seguinte forma: "Minha cabeça anda cheia de versos. Brotam sozinhos e eu coloco-nos no papel. .." (Farias, 2017).

${ }^{2}$ Retirado do livro Carolina: Uma biografia (Farias, 2017, p. 137).

${ }^{3}$ Trata-se do livro Quarto de despejo: Diário de uma favelada.

${ }^{4}$ Audálio Dantas foi o jornalista que viabilizou a publicação do primeiro e estrondoso sucesso de Carolina, Quarto de despejo.
} 
estudantes enquanto docente em um curso de psicologia em uma universidade federal da região Nordeste. O fio condutor que orienta o debate que ora proponho articula-se diretamente com o lugar social ocupado por mim enquanto docente e pesquisadora: mulher e branca. A partir deste lugar tenho tido interesse em problematizar sobre o modo como o conhecimento é produzido enquanto prática social e cultural carregada de significados e imersa num campo acirrado de disputas, a relação entre ciência, psicologia e política e a maneira como nossas escolhas - a elaboração de nossos planos de curso, bibliografias, exemplos trazidos em sala de aula, temas de pesquisa e modos de intervenção - determinam e produzem certos "regimes de representação" (Hall, 2016) responsáveis por fazer nossas e nossos estudantes se identificarem com determinadas narrativas e maneiras de pensar a realidade social em detrimento de outras.

De acordo com bell hooks (2013), há praticamente uma inexistência, em sala de aula, de discussões que levem em conta o modo como os valores de classes privilegiadas são impostos por meio de práticas pedagógicas tendenciosas. Tais parcialidades são refletidas na escolha de assuntos e na maneira como as ideias são partilhadas. Situo-me, assim, dentro de uma perspectiva de reparação, definição trazida por Grada Kilomba (2016) ao referir-se a um discurso público de Paul Gilroy ${ }^{5}$ e a explicação feita por este a respeito dos cinco mecanismos de defesa acionados pelos sujeitos brancos. A reparação, último mecanismo a ser apresentado dentro da constelação de possibilidades para se lidar com questões em torno da própria branquitude, diz respeito a um ato (de reparação) do mal causado pelo racismo e ancora-se em práticas de mudanças de estruturas, proposição de agendas, posições, relações subjetivas, por meio da tentativa de denunciar privilégios. $\mathrm{O}$ texto que escrevo tem a ver, assim, com o exercício de "desempalidecer" epistemes, compreendendo, desse modo, a centralidade dos discursos brancos na conformação da realidade social, do universo acadêmico, e o quanto estes criam os "outros", tornando-os insuficientes, primitivos, simplórios, atrasados, como nos ensina Frantz Fanon (2008). Nas palavras desse autor a respeito dos olhares/discursos brancos: "Tendo ajustado o microscópio, eles realizam objetivamente cortes na minha realidade" (Fanon, 2008, p. 108).
Desse modo, compartilho a ideia trazida por Pelúcio (2012) a respeito das identificações que são produzidas em estudantes durante a graduação - e que foram produzidas em mim ao longo de toda a minha trajetória acadêmica - a partir da leitura de textos escritos exclusivamente por autores brancos e homens, europeus ou norte-americanos em sua maioria, refletindo sobre a forma como certa colonização epistemológica foi desenhando e inscrevendo os jeitos de ver, sentir e pensar dentro do universo acadêmico. Nas palavras da autora:

É compreensível que nossas alunas e alunos, muitos deles vindos das classes média e média alta do Brasil, tenham dificuldade de se pensarem como 'os outros'. Cito as/os discentes, pois estou falando de projetos políticos de nação, que passam, evidentemente, pela formação educacional que tivemos, temos e que reproduzimos. Basta olharmos nossas salas nas universidades deste país para constatarmos que uma poderosa política racial orientou $o$ acesso à educação formal. Não costumamos pensar que uma sala de maioria branca ou socialmente branca trazia em silêncio uma política de raça. Em ambientes tão regularmente homogeneizados torna-se difícil se perceber como diferente ou refletir sobre a diferença (Pelúcio, 2012, p. 398).

Uma questão que se coloca a partir da reflexão trazida por essa autora diz respeito ao modo como raça nos organiza subjetivamente e socialmente. Para Schucman (2014), nós quase não perguntamos sobre quem é branca(o) ou o que é ser branca(o) num país como o Brasil, daí há muito sentido a discussão realizada por Silva (2007) ao mostrar que a força homogeneizadora da identidade normal é proporcional à sua invisibilidade. Autoras como Maia (2012), Schucman (2014) e Bento (2002) apontam para o fato de que poucos são os trabalhos que procuram compreender a experiência cotidiana de pessoas brancas enquanto pessoas racializadas. Ao falar sobre como os estudos realizados tanto no Brasil como nos Estados Unidos colocam a questão racial como um problema exclusivo de pessoas negras, Maia (2012) aponta para o fato de que, na produção teórica da área, a(o) branca(o) é um sujeito

${ }^{5}$ Esse autor fala de cinco mecanismos de defesa do ego acionados por sujeitos brancos a fim de que se tornem conscientes de sua branquitude. São eles: recusa, culpa, vergonha, reconhecimento e reparação (Kilomba, 2016). 
praticamente invisível, não desmascarada(o) em sua hegemonia pretensa e silenciosa.

Evidentemente, isso demonstra o que autores como Bento (2002), Silva (2007) e Hall $(1997,2006,2010)$ discutem ao falar da produção de identidades e diferenças: ser branca(o) age como um indicador universal, uma "norma transparente", usando a expressão de Bento (2002) e, por isso mesmo, uma essência, a partir da qual todas as diferentes raças se organizam. Neste caso, branquitude não é algo que mereça ser problematizado enquanto categoria hegemônica e portadora de privilégios. Daí Schucman (2014, p. 84) afirma que: "[...] a grande maioria dos psicólogos e pesquisadores são brancos e socializados entre uma população que se acredita desracializada, o que colabora para reificar a ideia de que quem tem raça é o outro e para manter a branquitude como identidade racial normativa". A autora convida-nos a compreender a branquitude como uma posição ocupada por sujeitos que foram, e ainda são, sistematicamente privilegiados no que diz respeito ao acesso a recursos materiais e simbólicos e que tal posição encarna-se na pretensa ideia de uma superioridade branca tão veiculada e popularizada em nosso país.

$\mathrm{O}$ que acontece com frequência é que existe omissão e silenciamento sobre o papel de brancas(os) na manutenção e reprodução das desigualdades raciais, fazendo com que estudos sobre o tema voltem-se somente para a desigualdade racial como um problema de negras(os). Nesse caso, para Bento (2002), tal silêncio tem como função última proteger os interesses que estão em jogo e que estão sendo disputados. De acordo com Liv Sovik (2004), a(o) brasileira(o) branca(o) não se constrange mais ao afirmar que possui um "pé na cozinha" fazendo referência à miscigenação como marca de nosso país, o que, em última instância, não diminui o poder e o prestígio de sua branquitude, lugar este confortável e privilegiado, a partir do qual se pode observar sem ser observada(o).

Outra questão que se coloca nesse artigo diz respeito às discussões realizadas por teóricas(os) que se inscrevem em debates pós-coloniais e decoloniais e que questionam o modo como a tradição científica moderna, ao considerar-se o único modelo de explicação do mundo, desperdiça experiências que não operam de acordo com sua lógica eurocêntrica. Tal lógica acaba por ser responsável pela produção da inexistência de diferentes sujeitos sociais, colocando impedimentos em suas narrativas e produções de conhecimentos. De acordo com Boaventura de Souza Santos (2008), não é possível que pensemos em uma justiça global sem, conjuntamente, pensarmos em justiças cognitivas. Justiças cognitivas têm a ver com a possibilidade de que determinados saberes costumeiramente alocados como irrelevantes sejam compreendidos como formas de interpretação do mundo tão potentes quanto aquelas ditadas pelo 'rigoroso conhecimento científico'.

Nossa tradição repousa no fato de que nossos povos indígenas e negros foram classificados como espécies não humanas durante uma parte considerável de nossa existência, a partir da intrusão de colonizadores em nosso continente. Isso implica em representações que ainda vigoram e que os colocam sempre ao lado da natureza, sendo que esta ainda é vista como aquilo que necessita de salvação, de domesticação. Entendida como escrava, a natureza precisa sempre de um colonizador que lhe diga o que deve ser feito. Destituída de cultura e incivilizada, ela pode ser constantemente violada.

A inclusão de realidades ausentes, invisibilizadas, ocultadas, sugerida por Santos (2008), para a psicologia e para as ciências humanas, de modo geral, implicaria numa descolonização epistemológica, teórica e metodológica uma vez que essa disciplina se consolidou através de teorias trazidas de fora para explicar nossa realidade e as pessoas que aqui viviam; prática que ainda continua presente em nosso cotidiano. O curso de psicologia é generificado e racializado, sendo composto, em sua maioria, por mulheres e estudantes brancas(os), daí Mayorga (2013), ao analisar a ausência de questões raciais em discursos de profissionais da psicologia de diferentes regiões do país, afirma: "sinto-me impelida a considerar que o acesso das mulheres ao campo profissional da Psicologia é a experiência de privilégio de algumas mulheres em relação às outras" (Mayorga, 2013, p. 184). Trazer discussões étnico-raciais para a psicologia tem justamente a ver com aquilo que Sueli Carneiro fala sobre a importância de investigar os efeitos perversos sobre a subjetividade de brancas(os), das representações imaginárias e simbólicas do corpo branco como instrumento de poder e de privilégios. Ela resume isso na pergunta: "Em termos de saúde mental, o que significam um ego e uma subjetividade inflados pelo sentimento de superioridade racial?" (Carneiro, 2011, p. 81).

O olhar atento para essas "outras" de que fala Mayorga (2013) vem sendo exercido por mim a partir da 
minha inserção nas discussões feministas e de gênero, sobretudo daquelas realizadas pelo feminismo da chamada terceira onda e também do pensamento negro. Esse feminismo acaba não tendo tanta expressividade no Brasil devido àquilo que certas(os) autoras(es) nomeiam por sua "articulação constitutiva" (Santos, Carvalho, Amaral, Borges, \& Mayorga, 2016). Atribuem isso ao fato de que a universidade brasileira historicamente ofereceu acesso limitado a determinados grupos sociais, impedindo classes populares e sujeitos negros de ingressarem e, assim, de contribuírem com vários debates, dentre eles, aqueles que se inserem no campo feminista. As marcas do racismo acadêmico e do pensamento colonizado acabam por invisibilizar ou mesmo não tomar como referência as produções de intelectuais como as mulheres negras, que são mencionadas em âmbito internacional e relegadas ao esquecimento, o que denuncia o modo como uma colonialidade epistemológica risca de nossas listas certas(os) autoras(es) e exalta outras(os). Kilomba (2016), ao tentar responder o porquê de a boca do sujeito negro ter sido, historicamente, amarrada, os motivos pelos quais tem que permanecer calado, atenta-se para o fato de que existe muito temor de que se deixe o sujeito colonizado falar. Quando fala, este obriga sujeitos brancos a ouvirem verdades desconcertantes que, provavelmente, não gostariam de escutar; segredos duros de serem apreendidos. "Segredos como a escravidão. Segredos como o colonialismo. Segredos como o racismo" (Kilomba, 2016, p. 177). Esse método de silenciar as vozes negras tem, como finalidade última, proteger o sujeito branco de reconhecer o "conhecimento do 'Outro'” (Kilomba, 2016, p. 177).

Além de Carolina Maria de Jesus, tenho trazido para a sala de aula e para as minhas pesquisas as narrativas de outras(os) escritoras(es) que romperam as esferas da abjeção, escritoras(es) como Conceição Evaristo e também poesias feitas por Stela do Patrocínio. De acordo com Judith Butler, em entrevista para Prins e Meijer (2002), corpos abjetos não são exclusivamente aqueles inscritos na heteronormatividade; mas aqueles cujas vidas não são consideradas vidas e cuja materialidade não é compreendida como importante. Butler chama a atenção para o fato de que esses corpos não possuem histórias. Ela exemplifica isso trazendo para o debate o fato de que frequentemente nos deparamos com nomes de alemães que cometeram crimes e o modo como a complexidade de suas histórias familiares e psicológicas passam a ser conhecidas, ao passo que turcos, em contrapartida, dificilmente possuem histórias familiares e psicológicas. A produção do abjeto se dá justamente no apagamento da história que ele porventura possa ter. Ao escolher mulheres negras e periféricas que facilmente são exterminadas em nosso país, cujas histórias, portanto, dificilmente seriam contadas - mas que, por diferentes motivos, foram - tenho apostado na tentativa de compreender os modos como são subjetivadas a partir de nossas formações culturais, sociais, políticas, econômicas.

O exercício de acompanhar a trajetória de Carolina, pelas(os) estudantes, num país que esforça-se por colocar mulheres negras num único lugar - o quarto de despejo - tem trazido como possibilidade problematizar a ainda tão atual invisibilidade do racismo presente em nossa sociedade e na formação em psicologia. No discurso de certas(os) discentes, em seminários e nos textos escritos pela primeira turma com a qual trabalhei, ficou nítida uma surpresa por parte de algumas e alguns sobre a existência tão brutal do racismo, algo que diziam desconhecer ou não achar tão massiva. Isso não deixa de ser surpreendente, pois de acordo com o Mapa da Violência de 2016, o estado no qual estou inserida é o maior responsável pelo assassinato de jovens negros do país, sendo que em 2014 foram assassinados 60 brancos e 1.702 negros por armas de fogo. Nas palavras de Waiselfsz (2016): "Vitimização negra neste estado: $1.028,2 \%$ (morrem assassinados, proporcionalmente, acima de 11 negros por cada branco)" (p. 60). Como demonstrava Carolina, há tantas décadas, ter uma pele branca acaba funcionando como um salvo-conduto: "Quando havia um conflito, quem ia preso era o negro. E muitas vezes o negro estava apenas olhando. Os soldados não podiam prender os brancos, então prendiam os pretos. Ter uma pele branca era um escudo, um salvo-conduto" (Jesus, 2014, p. 55). Ou ainda: "Os brancos, que eram os donos do Brasil, não defendiam os negros. Apenas sorriam achando graça de ver os negros correndo de um lado para outro. Procurando um refúgio, para não serem atingidos por uma bala" (Jesus, 2014, p. 59).

Essas discussões em sala de aula e em projetos de pesquisa têm permitido também atentar-se para a colonialidade epistemológica e a invisibilidade a qual ela lança determinados grupos sociais. Não foi indiferente o fato de que para ler a obra de Carolina Maria de Jesus foi necessário acessá-la em plataformas virtuais, uma vez que a biblioteca do campus não possuía 
nenhum exemplar da escritora. Isso chama atenção já que Audálio Dantas, ainda que morasse em São Paulo, era alagoano, como também pelo fato de que o campus possui o curso de Letras desde a década de 1970.

\section{O pensamento de fronteira ou paradigma 'outro' na perspectiva decolonial}

Não tenho de recorrer ao universal.

(Fanon, 2008, p. 122)

Di Cavalcanti, Oiticica e Frida Kahlo Têm o mesmo valor que a benzedeira do bairro. ("Sucrilhos", Criolo)

A diferença entre conquistadores e conquistadas(os) foi codificada a partir da ideia de raça (Bernardino-Costa \& Grosfoguel, 2016). Raça e racismo, desse modo, tornam-se princípios organizadores da acumulação de capital em escala mundial, tendo início em 1492 em nosso continente. É no século XVII que se vê formar o eurocentrismo como nova racionalidade capaz de legitimar a dominação e exploração imperial. O 'outro' que é construído a partir dessa classificação, não tem religião, escrita, voz, história, costumes, inteligência. Ela ou ele são atrasados, primitivos, bárbaros; são o próprio passado. Sob a ideia do eurocentrismo, repousa a colonialidade (do ser, do poder, epistemológica). Carolina vive isso na própria pele:

Ficava duvidando das minhas possibilidades porque os doutores de Coimbra diziam que os negros não tinham capacidade. Seria aquilo perseguição? Qual era o mal que os negros haviam feito aos portugueses? Por que é que eles nos odiavam, se os negros eram pobres e não podiam competir com eles em nada? Aquelas críticas eram complexas na mente do negro (Jesus, 2014, p. 47).

A colonialidade, assim, seria a face oculta dessa modernidade que, para autoras(es) decoloniais, não surge com a Reforma, Ilustração e Revolução Industrial. A modernidade é um projeto de dominação que tem início e sustenta-se por meio da exploração de outros continentes à época das navegações. Com seus discursos coloniais, praticados por jesuítas e, posteriormente, por uma pretensa racionalidade científica hegemônica, a modernidade ancora-se num processo de dissimulação, esquecimento e silenciamento frente a outras formas de conhecimentos e, ao fazer isso, cria a inferioridade. A emergência do primeiro grande discurso do mundo moderno é responsável por, a um só tempo, inventar e subalternizar grupos, impondo diferenças coloniais ao classificá-los em torno da ideia de raça. Do discurso colonial do século XVI e XVII vão se desenvolvendo práticas, ações, instituições que, no século XIX têm sua expressão máxima no racismo científico.

O que interessa aqui é pensar como que um pensamento de fronteira é criado como possibilidade de resistência frente às práticas e discursos hegemônicos coloniais. De acordo com Bernardino-Costa e Grosfoguel (2014), as fronteiras não se resumem aos espaços nos quais as diferenças coloniais podem ser reinventadas. Fronteiras também são locus enunciativos nos quais são formulados conhecimentos que se originam a partir de perspectivas, cosmovisões e experiências de sujeitos subalternizados. Dizem eles: "O locus de enunciação não é marcado unicamente por nossa localização geopolítica dentro do sistema moderno/colonial, mas é também marcado pelas hierarquias raciais, de classe, gênero, sexuais etc. que incidem sobre o corpo" (Bernardino-Costa \& Grosfoguel, 2014, p. 19). Esse pensamento de fronteira, ou paradigma 'outro' (Mignolo, 2000) não tem autoria de referência ou origem comum. Para Walter Mignolo (2000), o que ele tem em comum é o fato de ser fruto daquelas(es) que têm vivido ou aprendido no corpo o trauma, a falta de respeito, a ignorância em prol de valores como progresso, bem-estar, desenvolvimento; discursos da tradição científica que são impostos à maioria dos habitantes do planeta como se fossem verdadeiros, universais. Trata-se da ferida aberta de que nos fala Anzaldúa (2005).

O pensamento de fronteira ou paradigma 'outro' tem ligação direta com o ato de reaprender a ser. Isso só pode ser empreendido por aquelas(es) que padeceram os desígnios dos conhecimentos imperiais: teologia, filosofia secular e racionalidade científica, trata-se, assim de pensar a partir da dor provocada pela diferença colonial. Essa ferida Carolina Maria de Jesus conhece bem: "A escravidão era como cicatriz na alma do negro" (2014, p. 61), dizia ela. O pensamento de fronteira é aquele formulado pelas(os) deserdadas(os) da modernidade, pensamento da dor e da fúria, da fratura de histórias, memórias, 
subjetividades, biografias (Mignolo, 2000). Ele possui efeito de denúncia. É isso o que faz Carolina quando conta que seu avô, Benedito, soldo da escravidão, parecia-lhe um vulto que saía da senzala, alquebrado, desiludido, ciente de que havia trabalhado para enriquecer o colonizador, desgostoso porque os oito filhos não estudaram, pois eram proibidos de fazê-lo. A Constituição de 1924 é uma prova disso: ela impedia a população africana e escravizada de frequentar escolas no Brasil e, anos depois, uma lei ${ }^{6}$ proibia de frequentar escolas públicas pessoas que padecessem de moléstias contagiosas, escravos e africanos, mesmo que livres (Santos et al., 2016).

Tais pensamentos trazem a necessidade de se conceber o conhecimento como geopolítico ao invés de universal. Trata de questionar, com isso, a suposta universalidade, desinteresse e não localização dos paradigmas eurocêntricos hegemônicos, mostrando que os lugares nos quais são produzidos conhecimentos, são circunscritos em poderosas arenas de poder, ferrenhamente disputadas. Com isso, nega-se potencial epistêmico àquelas(es) que foram coloca$\mathrm{da}(\mathrm{o}) \mathrm{s}$ às margens daquilo que é considerado ciência. O que se coloca em questão é que as línguas e as ideias coloniais do saber moderno não são suficientes para explicar as diferentes realidades, uma vez que estão limitadas a uma visão parcial da própria história, uma visão provinciana - a saber, europeia. Um paradigma 'outro' é um paradigma de disrupção. É produzido em lugares de pensamento (África, Ásia, América), lugares de história, memória, dor, línguas e saberes diversos (Mignolo, 2000). Esses lugares entroncam-se na descontinuidade da tradição clássica que coloca Cristóvão Colombo, com suas leituras antigas e medievais, assim como o cristianismo, não mais como parâmetros, mas como tradições que pouco importavam para aquelas(es) que aqui se encontravam. Assim:

Um "paradigma otro" marca la discontinuidad em la historia de la modernidad contada desde la perspectiva de la propia modernidad, e introduce la mirada opuesta. No, digamos, la mirada de Colón mirando ese objeto extraño, em el agua, que se acercaba havia ellos. Esas dos miradas se ligaron, se entrelazaron en una relación de poder; se plantó la semilla de la colonialidad del poder y com ella el paradigma silenciado durante mucho tiempo de quienes ven el mundo desde las costas a la que llegan los barcos, los ferrocarriles, los bancos, los aviones (Mignolo, 2000, p. 32).

Com isso, de acordo com Bernardino-Costa e Grosfoguel (2016), a perspectiva decolonial têm como função restituir a fala e a produção teórica e política de sujeitos que até então foram vistos como aqueles que não possuíam condições de falar e produzir teorias bem como projetos políticos. O pensamento de fronteira é, pois, aquele gestado por mulheres e homens que se encontram "do outro lado" e, com isso, observam a aproximação de estrangeiras(os), barcos, aviões e armas. É necessário, portanto, que haja reconhecimento das reações heterogêneas dos sujeitos subalternizados à colonialidade do poder (Bernardino-Costa \& Grosfoguel, 2016). Para Mignolo (2000), o pensamento de fronteira está em consonância com aqueles produzidos por "mulheres de cor" como Anzaldúa, Moraga, bell hooks, dentre outras. Acredito que Carolina Maria de Jesus possa ser colocada entre essas mulheres que produzem conhecimento a partir da dor provocada pela ferida aberta da diferença colonial. Em sua fala na reitoria da Universidade Federal da Bahia neste $a^{7}{ }^{7}$, Angela Davis chama a atenção para o fato de que os escritos de Carolina, ao revelarem a "a escravatura atual" (Jesus, 2007, p. 32) - a fome - trazem a dimensão interseccional antes mesmo de essa concepção ser utilizada pelas feministas.

Devemos ter em mente também que 1914, ano do nascimento de Carolina, é aquele em que pela primeira vez o termo "eugenia" passou a ser utilizado no Brasil, afinal, a abolição tinha acontecido há apenas vinte e seis anos. Isso permite que Carolina testemunhe as brutalidades que vêm coladas à abolição, os medos vividos pela elite brasileira frente ao fato de que o Brasil compunha-se por uma população negra, as conversas das pessoas comuns, daquelas que se colocam a favor e também contra a abolição. De acordo com Werneck (2016), inicialmente vinculado à medicina, o racismo científico do início do século XX e seu ideal eugênico faz parte de uma estratégia que logo ganhou adeptas(os) no país com vistas a embranquecer a raça e, com isso, ordenar-se junto ao

\footnotetext{
${ }^{6}$ Lei no 1 , de 4 de janeiro de 1837.

${ }^{7}$ Recuperado de https://www.youtube.com/watch?v=2vYZ4IJtgD0
} 
ideário de progresso e desenvolvimento. Perspectivas essas que fundamentam-se na luta contra a degeneração provocada pela mistura de raças. Isso permite a criação de estruturas políticas, práticas e normas (que ali começam e vigoram até hoje) que institucionalizam o racismo e, com isso, o naturalizam. De acordo com Lélia Gonzalez (1988):

o racismo estabelece uma hierarquia racial e cultural que opõe a "superioridade" branca ocidental à "inferioridade" negroafricana. A África é o continente "obscuro", sem uma história própria (Hegel); por isso, a Razão é branca, enquanto a Emoção é negra. Assim, dada a sua "natureza sub-humana", a exploração sócio-econômica dos americanos por todo o continente é considerada "natural" (p. 77).

Como bem lembra Bento (2002), frente a esse medo, a política de imigração europeia trouxe para cá quase quatro milhões de imigrantes europeus em trinta anos, o equivalente ao número de africanas(os) trazidas(os) em três séculos. Carolina conta-nos isso em seu relato: "Após a libertação, os portugueses ficaram apavorados com medo dos negros. Era o reverso da medalha para eles que foram os leões e eram obrigados a transformar-se em ovelhas. Milhares deixaram o país e o Brasil ficou à deriva" (Jesus, 2014, p. 61).

Ao ler o livro de Angela Davis, Mulheres, raça e classe, chamou-me atenção a riqueza de material trazido por essa autora que reproduzia falas de ex-escravizadas(os) contando as agruras vividas por elas(es) e por outras(os) negras(os). Em Diário de Bitita, livro no qual Carolina volta-se para sua infância e adolescência, é possível observar que à sua voz, muitas outras se somam no entendimento da escravidão; vozes essas que estavam coladas à experiência de terem sido escravizadas um dia, como a de seu avô, Benedito. Diante disso, é possível dizer que Carolina fala diretamente do lugar da dor provocado pela escravidão, ela vive os efeitos desse período histórico ainda muito nova: "Eu estava com cinco anos, achava esquisito aquelas cenas antagônicas, a minha mentalidade embrionária não me auxiliava a compenetrar aquelas divergências" (Jesus, 2014, p. 63). De tão debatido nos lugares por onde passava, o tema da escravidão chega a causar-lhe exaustão, mesmo assim, Carolina decide-se estudá-lo cada vez mais. Seu relato mostra como a branquitude é defendida pelas pessoas de Sacramento, Minas Gerais, cidade onde nasceu - professoras, juízes etc. Em sua infância, ela acompanha a insatisfação de professoras brancas que são obrigadas a receber estudantes negras(os) em suas escolas, as brigas decorrentes e o modo como ficavam indignadas: “- Os abolicionistas, vejam o que fizeram! Essa gente agora pensa que pode falar de igual para igual. Eu, na época da abolição, tinha mandado toda essa gente repugnante de volta para a África" (Jesus, 2014, p. 43).

Carolina, ao produzir sua narrativa, mostra as dificuldades decorrentes da escravidão: o uso e abuso de álcool, o trabalho excessivo, cansativo e mal remunerado, os estupros e violações as quais estavam sujeitas as mulheres negras, praticados pelos "[...] filhos do senhor Pereira, Moreira, Oliveira, e outros porqueiras que vieram de além-mar" (Jesus, 2014, p. 38), o modo como mulheres negras compunham a dinâmica econômica e sexual na qual se sustentava o regime escravocrata, como também nos relata Davis (2016). Conta-nos também as humilhações, xingamentos, prisões arbitrárias, falta de acesso a bens materiais, precarizações, enfim, todas as formas de exclusão e discriminação que mulheres e homens negras e negros continuavam a viver em nosso país, a despeito da abolição; diz ela:

Quando os pretos falavam: - Nós agora estamos em liberdade. - Eu pensava: "Mas que liberdade é essa se eles têm que correr das autoridades como se fossem culpados de crimes? Então o mundo já foi pior para os negros? Então o mundo é negro para o negro, e branco para o branco!" (Jesus, 2014, p. 59).

A própria Carolina, relato vivo disso, condenada a viver suja em função do trabalho precário que executava e da falta de condições para comprar sabonete e ter água, demonstrando a sistemática divisão racial do trabalho às quais negras e negros estiveram circunscritos para que o capital pudesse concentrar-se nas mãos de brancas(os). Esses últimos, únicos a terem salário e a ocuparem postos de mando na administração colonial. Trabalho pago era privilégio de brancas(os). Assim, regiões e populações incorporadas no novo mercado mundial e colonizadas sob domínio europeu permaneciam basicamente sob relações não salariais de trabalho (Quijano, 2000).

Por outro lado, Carolina também aponta para outros discursos - como o de Rui Barbosa, que menciona com frequência em seu diário, que era lido em voz 
alta por Manoel Nogueira a quem ela descrevia como "mulato", o "meio-termo da sociedade" (Jesus, 2014, p. 43). Manoel Nogueira lia, sentado na porta de sua casa, trechos de O Estado de São Paulo; informalmente, ele instruía Carolina a partir dessas leituras e do incentivo para que negras(os) se alfabetizassem a fim de não serem mais subjugadas(os). Seu avô a ensinava sobre os horrores da escravidão quando nas noites quentes falava de Palmares, Zumbi e das lutas de seu povo.

Importa, pois, pensar em como Carolina é capaz de recriar a si mesma apesar da mentalidade eugenista e higienista de sua época, que retirava forçosamente a população subalternizada das ruas e a enfiava em favelas, não lhes permitindo ter acesso a bens materiais básicos (saúde, moradia, educação) e também simbólicos. Importa também denunciar o fato de que passados tantos anos da publicação de seus livros, pouca coisa foi modificada, mostrando, como afirma Angela Davis, que escritos e ideias elaborados por mulheres negras, dentre as quais a própria autora se insere, ainda que pareçam ter caráter de premonição, mostram, na verdade, que pouca transformação ocorreu. Se a escrita de Carolina parece visionária já que antecipava inúmeras das discussões que hoje são realizadas dentro e fora da academia e revelava diversas violências praticadas em nossa sociedade, a contemporaneidade dessa discussão, passados tantos anos da publicação de suas ideias, demonstra que estamos atrasadas(os), que fizemos pouco e que ainda estamos desfrutando de privilégios.

\section{Escritas de si para romper as amarras da abjeção}

Em outro trabalho (Oliveira, 2017), mencionei um evento ocorrido na Academia Carioca de Letras no ano de 2017, no qual Carolina seria homenageada. Dias depois da homenagem circulava nas redes sociais textos que revelavam um desconfortável acontecimento que se deu durante a homenagem. Um desses textos foi escrito pela poeta, atriz e cantora Elisa Lucinda ${ }^{8}$ e foi publicado na rede social Facebook para dar visibilidade à situação e também como forma de protesto. Nele, Lucinda escreve um texto visceral, expondo sua perplexidade diante da fala de um professor de literatura, membro da referida Academia, convidado a participar do evento em homenagem à escritora. Responsável pela fala inicial, o acadêmico afirmou, com toda a convicção, que aquilo que Carolina escrevia não era literatura, era apenas um diário com períodos curtos e pobres. Este velho e, neste caso, audacioso, - exercício de classificação e hierarquização tem história, como já vimos. Ele se assenta na mesma vara de medir e classificar (Mignolo, 2007) utilizada à época da colonização e tem uma indubitável função: levantar muros, dizer quem pode participar do jogo, produzir aquelas(es) que são indignas(os) de falar.

Diante disso, importa que compreendamos que o processo de redução ativa das pessoas que se inicia com a colonização e vigora até hoje com práticas de colonialidade, tem relação direta com a ideologia da supremacia racial branca e, tal como já apontava Aimé Césaire (1978, p. 2), ela é como uma gangrena, cujo foco de infecção se alastra, mantendo e reproduzindo uma "arrogância racial encorajada".

Produzir faveladas(os) e analfabetas(os) tem sido um antigo exercício realizado por brancas(os), afinal a favela é o lugar onde despejamos nossos detritos e no qual produzimos faveladas(os), de modo a nos constituirmos como "pessoas de bem" (Azeredo, 2008). Esses grupos são socializados, desde que adentram na escola (quando permitido) de modo a acreditarem que tudo que necessitam é ter disposição para o trabalho físico, sendo criados para permanecer numa subclasse, para não ter escolhas, para contribuir com sua mão-de-obra explorável e descartável, para ficarem circunscritos aos quartos de despejos que são esquadrinhados para elas(es). Ao saírem dessa posição, são duramente repreendidas(os) (hooks, 2015), colocadas(os) a todo custo naqueles lugares que, historicamente, lhes têm sido designados. Debruçar-se sobre a vida e a obra de Carolina Maria de Jesus tem a ver, portanto, com o ato de testemunhar que a(o) abjeta(o), ao contrário do que se procura fazer crer, não é muda(o), ela(e) usa as palavras que estão disponíveis no mundo, como bem aponta Azeredo (2008) ao falar da obra da escritora. $\mathrm{A}(\mathrm{o})$ abjeta(o), ao projetar sua voz, produz sentidos sobre a realidade social, propõe explicações que fogem dos tão bem estruturados sistemas explicativos eurocêntricos que frequentemente não encontram respostas para as mais diversas perguntas que são feitas. A partir de sua dor, ele pulsa e faz pulsar.

A descolonização epistemológica em psicologia teria a ver com a tentativa de realizar uma operação que consistiria em se desapegar do eurocentrismo e

${ }^{8}$ Recuperado de https://www.facebook.com/elisalucinda/posts/ 1289284134489348 
abrir-se para outras experiências, histórias, cosmovisões e teorias que são costumeiramente tornadas menores, abjetas, desqualificadas. Essa é uma ideia defendida por Pereira (2015). Segundo esse autor, devemos fustigar a pedagogia que preconiza a simples adesão ao cânone. Devemos ser capazes de revisar e torcer silêncios produzidos por teorias do Norte Global que se pretendem uni-versais. Devemos ir atrás do pluri-versal e transdisciplinar, abrindo nossos ouvidos para teorias-outras, deixando que os discursos produzidos nas margens possam, segundo ele, afetar a própria textura do pensamento. De acordo com Schucman e Martins (2017), com o aumento sistemático de discussões sobre raça dentro do campo da Psicologia e a partir de uma perspectiva formulada por pensadoras(es) negras(os) voltada para esse campo de conhecimento, tem sido possível realizar mudanças fundamentais para as discussões sobre relações raciais. Contudo, essas(es) autoras(es) apontam para o fato de que nossa categoria, sobretudo em relação à formação, tem dado pouca atenção a esses debates e formulado poucas respostas para a questão do racismo. Aqui, acrescento, a psicologia social tem diante de si um amplo campo de possibilidades para formular outras texturas teóricas, indagações inéditas, abrindo-se para pensadoras(es) que habitam lugares fraturados dos quais, ainda timidamente, estamos nos aproximando.

\section{Referências}

Anzaldúa, G. (2005). La conciencia de la mestiza/Rumo a uma nova consciência. Revista Estudos Feministas, 13(3), 704-719.

Azeredo, S. (2008). A favela escrita de Carolina Maria de Jesus. Mental, 11, 167-175.

Bento, M. A. (2002). Branqueamento e branquitude no Brasil. In I. Carone \& M. A. Bento, (Orgs.), Psicologia social do racismo: Estudos sobre branquitude e branqueamento no Brasil (pp. 25-58). Petrópolis, RJ: Vozes.

Bernardino-Costa, J., \& Grosfoguel, R. (2006). Decolonialidade e perspectiva negra. Revista Sociedade e Estado, $31(1), 15-24$.

Carneiro, S. (2011). Colorindo egos. In S. Carneiro, Racismo, sexismo e desigualdade no Brasil (pp. 78-82). São Paulo, SP: Selo Negro.

Césaire, A. (1978). Discurso sobre o colonialismo. Lisboa: Livraria Sá da Costa Editora.

Davis. A. (2016). Mulheres, raça e classe. São Paulo, SP: Boitempo.

Fanon, F. (2008). Pele negra, máscaras brancas. Salvador, BA: EDUFBA.

Farias, T. (2017). Carolina: Uma biografia. Rio de Janeiro, RJ: Malê.

Fernandez, R. A. (2014). Entrevista Audálio Dantas. Scripta, 18(35), 305-314.

Gonzalez, L. (1988). A categoria político-cultural da amefricanidade. Tempo Brasileiro, (92-93), 69-82.

Hall, S. (1997). A centralidade da cultura: notas sobre as revoluções culturais de nosso tempo. Educação \& Realidade, 22(2), 1997, 15-46.

Hall, S. (2006). A identidade cultural da pós-modernidade. Rio de Janeiro, RJ: DP\&A Editora.

Hall, S. (2010). El espectáculo del “Otro”. In E. Restrepo, C. Walsh, \& V. Vich (Orgs.), Sin garantias: Trayectorias y problemáticas en studios culturales (pp. 419-446). Quito: Envión.

Hall, S. (2016). Cultura e representação. Rio de Janeiro, RJ: Apicuri.

hooks, b. (2013). Ensinando a transgredir: A educação como prática da liberdade. São Paulo, SP: WMF Martins Fontes.

hooks, b. (2015). Escolarizando homens negros. Revista Estudos Feministas, 23(3), 677-689.

Jesus, C. M. (2007). Quarto de despejo: Diário de uma favelada. São Paulo. SP: Ática.

Jesus, C. M. (2014). Diário de Bitita. São Paulo, SP: Sesi.

Kilomba, G. (2016). A máscara. Caderno de Literatura em Tradução, 16, 171-180.

Maia, S. (2012). Identificando a branquidade inominada: corpo, raça e nação nas representações sobre Gisele Bündchen na mídia transnacional. Cadernos Pagu, 38, 309-341.

Mayorga, C. (2013) Sobre mulheres, psicologia, profissão e a insistente ausência das questões raciais. In L. Lhullier. (Org.), Psicologia: Uma profissão de muitas e diferentes mulheres (pp. 173-200). Brasília, DF: Conselho Federal de Psicologia. 
Mignolo, W. D. (2000). "Un paradigma otro": colonialid global, pensamiento fronterizo y cosmopolitismo crítico. In W. D. Mignolo, Historias locales/diseños globales: Colonialidad, conocimientos subalternos y pensamiento fronterizo (pp. 19-60). Madri: Ediciones Akal.

Mignolo, W. D. (2007). La idea de América Latina: La herida colonial y la opción decolonial. Barcelona: Editorial Gedisa.

Oliveira, E. C. S. (2017). Pistas de Carolina Maria de Jesus para a intervenção psicossocial. Anais do Seminário Internacional Fazendo Gênero, 11, 1-10.

Pelúcio, L. (2012). M. Subalterno quem, cara pálida? Apontamentos às margens sobre pós-colonialismos, feminismos e estudos queer. Contemporânea: Revista de Sociologia da UFSCAR, 2(2), 395-418.

Pereira, P. P. G. (2015). Queer decolonial: quando as teorias viajam. Contemporânea, 5(2), 411-437.

Prins, B., \& Meijer, I. C. (2002). Como os corpos se tornam matéria: Entrevista com Judith Butler. Revista Estudos Feministas, 10(1), 155-167.

Quijano, A. (2000). Colonialidad del poder, eurocentrismo y América Latina. E. Lander, (Org), La colonialidad del saber: Eurocentrismo y ciencias sociales (pp. 201-246). Buenos Aires: Clacso.

Santos, B. S. (2002). Para uma sociologia das ausências e das emergências. Revista Crítica de Ciências Sociais, 63, 237-280.

Santos, L. C., Carvalho, A. B., Amaral, J. G., Borges, L. A., \& Mayorga, C. (2016). Gênero, feminismo e psicologia social no Brasil: Análise da Revista Psicologia \& Sociedade. Psicologia \& Sociedade, 28(3), 589-603.

Schucman, L. V. (2014). Sim, nós somos racistas: Estudos psicossociais da branquitude paulistana. Psicologia \& Sociedade, 26(1), 83-94.

Schucman, L. V., \& Martins, H. V. (2017). A psicologia e o discurso racial sobre o negro: Do "objeto da ciência" ao sujeito político. Psicologia: Ciência e Profissão, 37, 172-185.

Silva, T. T. (2007). A produção social da identidade e da diferença. In T. T. Silva (Org), Identidade e diferença: a perspectiva dos Estudos Culturais (pp. 73-102). Petrópolis, RJ: Vozes.

Sovik, L. (2004). Aqui ninguém é branco: hegemonia branca e media no Brasil. In V. Ware (Org), Branquidade: identidade branca e multiculturalismo (pp. 363-386). Rio de Janeiro, RJ: Garamond.

Waiselfisz, J. J. (2016). Mapa da violência 2016: Homicídios por armas de fogo no Brasil. Brasília, DF: Flacso.

Werneck, J. (2016). Racismo institucional e saúde da população negra. Saúde e Sociedade, 25(3), 535-549.

\section{Érika Soares Oliveira}

Docente no Instituto de Psicologia da Universidade Federal de Alagoas (Ufal), Maceió - AL. Brasil.

E-mail: oliveiraerika000@gmail.com

(1) https://orcid.org/0000-0003-4877-0971

Endereço para envio de correspondência:

Universidade Federal de Alagoas, Campus AC Simões, Instituto de Psicologia. Av. Lourival Melo Mota, s/n,

Tabuleiro do Martins. CEP: 57072-900. Maceió - AL. Brasil.

Recebido 17/08/2018

Aceito 08/05/2019

Received $17 / 08 / 2018$

Approved 08/05/2019

Recibido 17/08/2018

Aceptado 08/05/2019 
Psicologia: Ciência e Profissão 2020 v. 40, e212106, 1-12.

Como citar: Oliveira, E. S. (2020). O Pensamento de Fronteira de Carolina Maria de Jesus. Psicologia: Ciência e Profissão, 40, 1-12. https://doi.org/10.1590/1982-3703003212106

How to cite: Oliveira, E. S. (2020). Carolina Maria de Jesus’ Border Thinking. Psicologia: Ciência e Profissão, 40, 1-12. https://doi.org/10.1590/1982-3703003212106

Cómo citar: Oliveira, E. S. (2020). El Pensamiento de frontera de Carolina Maria de Jesus. Psicologia: Ciência e Profissão, 40, 1-12. https://doi.org/10.1590/1982-3703003212106 